\title{
Estudo de ciberjornais de Espanha e Brasil
}

\author{
Raquel Gomes de Oliveira
}

\section{Resumo}

Este trabalho pretende mostrar de maneira sintetizada a estrutura das redações dos jornais digitais, analisando quatro estudos de casos: os espanhóis $E l$ Pais.com e La Vanguardia.es, e os brasileiros FolhaOnline e O Globo.com. Os objetivos são conhecer como estes jornais digitais nasceram, a que grupos de comunicação pertencem, como é a rotina de trabalho de seus profissionais, e também analisar como são utilizados os recursos multimídia, e a participação dos leitores, demonstrando, dessa maneira, quais são as semelhanças e diferenças entre esses diferentes veículos de comunicação. O estudo se baseia em entrevistas realizadas com os jornalistas das redações digitais e análises de material documental sobre os ciberjornais.

Palauras-chave:

Redações, Ciberjornal, Internet, Multimídia e leitores

\section{Cyber papercase studies in Spain and in Brazil}

\section{Abstract}

This work intends to demonstrate in synthesized way the structure of the redactions of digital journals analyzing four studies of cases: the Spanishes: El Pais.com and La Vanguardia.es, and the Brazilians: FolhaOnline and OGlobo. com. The objectives are to know as these digital periodicals had been born, which groups of communication belong, how is the work's routine of its professionals, and also to analyze what are the multimedia use, the participation of the readers, demonstrating in this way, which are the similarities and differences between these different vehicles of communication. The methodology used is based on interviews with the journalists of digital writings and analyses of documentary material of web journals.

Sobre a autora

Doutoranda da Universidade Autônoma de Barcelona. raqgomes@yahoo.com.br
Key words:

Redactions, Cybernewspaper, Internet, Multimedia and readers 
Primeiramente se expõem os quatro casos estudados e posteriormente se apresentam as reflexões sobre os ciberjornais e o ciberjornalismo. Devido à redução deste material de um capítulo de tese doutoral para um artigo de revista se suprimiram teorias e introduções sobre o tema para ir direto ao que o artigo se propõe: os estudos de casos e o que podemos aprender com eles.

\section{- Grupo Godó e La Vanguardia}

A história que precede o Grupo Godó começa com o jornal La Vanguardia, propriedade da família Godó, desde que se fundou em $1^{\circ}$ de fevereiro de 1881 , em Barcelona, se constituindo o produto mais importante do grupo.

Em seu $126^{\circ}$ aniversário, em fevereiro de 2007, La Vanguardia lançou um novo formato do jornal, que evoluiu em muitos aspectos, porém segue com os mesmos valores. La Vanguardia se adapta à evolução tecnológica, se redesenha, reforça a infografia e a fotografia, e traz um renovado tratamento da informação, mais diverso e cuidado.

\section{La Vanguardia.es}

Segundo seu modelo de negócio, são três as fases históricas de La Vanguardia.es. A primeira foi a criação, em junho de 1995, da edição on-line do centenário jornal barcelonês, cuja principal característica era que todo seu conteúdo era gratuito. Os dois jornalistas responsáveis pelo jornal digital tinham como principal atividade publicar o jornal impresso na web. Desde sua origem, o jornal eletrônico ofereceu acesso ao fundo histórico de La Vanguardia, o mais antigo da Espanha, disponibilizando a consulta em formato PDF de todas as edições do jornal desde sua criação em 1881 até a atual.

La Vanguardia.es se transformou muito rapidamente em seus primeiros cinco anos, acompanhando um crescimento natural em que passou o surgimento da internet. Em 2000, contando com 15 jornalistas em sua planilha, perceberam que o negócio em internet passava por uma crise. Passaram então a reduzir o pessoal e a revisar o modelo de negócio. Em fevereiro de 2003, o ciberjornal entrou em sua segunda fase. Estabeleceram um nível de consulta gratuita mediante registro prévio de usuários para toda a produção digital, as notícias do dia e da semana corrente. $\mathrm{O}$ acesso às notícias anteriores aos últimos sete dias apenas era possível como assinante on-line ou do jornal impresso.

Depois da redução de profissionais, do fechamento dos multimídias e, conseqüentemente, de uma estagnação do crescimento dos usuários e assinantes, decidiram em junho de 2006 passar por uma nova reorientação do modelo de negócio. Com uma mudança de desenho expressivo, pretenderam principalmente separar tudo o que
O jornal eletrônico ofereceu acesso ao fundo histórico de La Vanguardia, disponibilizando a consulta em formato PDF de todas as edições do jornal desde 1881 
é produção digital do jornal papel. Assim, tudo o que foi produzido pela redação digital tornou-se gratuito e tudo o que se refere às edições impressas tem acesso pago.

Os leitores são muito atentos e sempre comentam suas opiniões. Assim, as transformações pautadas pela redação para a maioria do ciberjornal são baseadas em necessidades do usuário e da equipe de profissionais que está por detrás de La Vanguardia.es.

\section{Equipes Responsáveis}

A empresa Iniciativas Digital Media (IDM) elabora La Vanguardia.es para a empresa La Vanguardia Edições. Por razões de ordem empresarial e sindical, houve um tempo em que os jornalistas de ambos os lugares não podiam trabalhar conjuntamente. Isso deixou de ser tão estrito e atualmente há o intercâmbio de informação entre ambas as redações. $\mathrm{O}$ jornal remete em suas páginas à consulta da web, cada vez que uma informação do papel tem prolongação no digital, seja em um vídeo, uma enquete, um documento etc.

A equipe da redação digital passou por muitas mudanças desde 2006, ano em que houve uma modificação também no jornal impresso. A partir desse momento, a redação teve sua planilha incrementada, aumentando de 11 jornalistas em 2006, para 21 jornalistas e mais 7 colaboradores, em janeiro de $2008^{1}$.

La Vanguardia.es está agora organizada em três áreas, cada uma delas com um chefe de seção, que são: Atualização, com 12 jornalistas; Informação Local (vídeo), com cinco jornalistas; e Participação, com dois jornalistas e dois colaboradores. Cada jornalista tem sua ocupação específica, porém todos são capazes de exercer qualquer atividade. Seus salários estão baseados em acordo, conforme o sindicato dos jornalistas determina, e só se distinguem pela antiguidade na casa, e não por sexo ou função.

\section{Grupo PRISA e El País.com}

O Grupo PRISA é o maior grupo de educação, informação e entretenimento (imprensa, rádio, audiovisual) nos mercados de língua espanhola e o único totalmente ibero-americano. É um dos líderes em imprensa na Espanha, principalmente através do El País, jornal que nasceu em 4 de maio de 1976 e rapidamente se converteu em um dos jornais espanhóis de maior difusão e influência. Foi precursor na adoção de usos jornalísticos como o Livro de Estilo, a figura do Defensor do Leitor (ombudsman) e o Estatuto da Redação.

El País tem sua sede em Madrid, onde estão a redação, as oficinas centrais e uma de suas plantas de impressão, além de imprimir suas edições em diversas cidades de Espanha, e igualmente em Alemanha, Bélgica, México e Argentina. O jornal também tem uma edição em inglês. Ao mesmo tempo, colabora com o francês $L e$ Monde e o italiano La Republica.

${ }^{1}$ A pesquisa junto aos jornais espanhóis iniciou em 2006, e aos jornais brasileiros, em janeiro de 2007. Os dados que constam neste artigo sobre a situação das redações, datam de janeiro de 2008. 
Em março de 2007, o diretor do jornal, Javier Moreno, convocou um reduzido porém heterogêneo grupo de jornalistas e lhes lançou um objetivo muito claro: fazer um jornal que se saiba que é $E l$ País, mas que se veja que mudou para melhor. O ponto de partida foi uma sondagem, para perguntar aos leitores.

A mudança seria notável: agrupar em uma primeira parte a informação internacional, nacional e econômica, com a idéia de afiançar as características próprias do jornal e oferecer uma informação sóbria e direta; apoiada nos novos formatos e linguagens, mas com a contundência que tem um jornal que dá aos seus leitores chaves para compreender o mundo que os rodeia.

\section{El País.com}

A versão digital do jornal é administrada pela Prisacom, empresa encarregada dos conteúdos do Grupo PRISA no suporte digital e através de todo tipo de dispositivos (computador, telefone celular, PDA, televisão, CDs). Criada emo 2000, a Prisacom ampliou e enriqueceu a presença das principais empresas da PRISA na área de novos meios de comunicação. O principal produto de Prisacom é o El País.com.

El País esperou até cumprir seus 20 anos, em 4 de maio de 1996, para estrear na internet. O El País digital, diferente de outros ciberjornais, já contava com uma equipe de nove jornalistas e mais dois técnicos para o trabalho de reprodução on-line.

O grande desafio inicial foi como descobrir a melhor forma de fazer rentáveis esses produtos eletrônicos de evolução rápida. Começou de forma gratuita, mas não demorariam em modificar seu modelo. Em fevereiro de 2001, se publicou uma nova versão que renovou completamente sua arquitetura de navegação, incorporando importantes avanços tecnológicos e estreando uma oferta de gráficos animados. Mudanças que se uniram com a decisão de converter o ciberjornal em pago.

Em 18 de novembro de 2002, a maioria dos seus conteúdos era exclusivamente para assinantes. Em junho de 2005, El País digital passou a estar muito mais aberto com um reajuste de modelo, decisão que trouxe um grande incremento de assinantes.

O ciberjornal passou a ter como permanentes pequenas transformações para melhorar a qualidade de sua web. No entanto, a mudança do El País e, conseqüentemente, de sua versão digital, mais anunciada e comentada foi em 21 de outubro de 2007.

O jornal estreou na rede como El País.es, mas junto às mudanças em outubro de 2007, se rebatizou para El País.com, para ressaltar sua importância e internacionalidade. Entre as mudanças há novidades de desenho, incremento dos multimídia e incorporação de novas vias para potencializar a participação ativa dos usuários. 
Os internautas podem opinar, perguntar e debater a nova seção "Participa", ou enviar suas opiniões, fotos ou vídeos sobre os principais temas da atualidade através do espaço "Eu, jornalista". Um grupo de jornalistas da Prisacom filtra as informações para garantir que estas sejam verazes. ElPaís.com é o primeiro meio espanhol que abriu esse espaço informativo aos leitores. Qualquer usuário pode criar e manter sua página pessoal em forma de blog e construir comunidades agrupadas por temas de interesses com outros internautas.

Desde 15 de novembro 2007, os leitores podem acessar grátis desde El País.com a todos os conteúdos da edição impressa (salvo PDF). Uma transformação que aspira a incrementar os ingressos publicitários derivados de uma maior audiência na rede.

\section{A estrutura interna e a equipe responsável de EI País.com}

Não foi possível saber informações precisas sobre a redação desse jornal digital. Na visita feita à redação se entrevistou somente alguns jornalistas, a chefa de redação não estava disponível e os contatos feitos por e-mail não deram resultado. Sabemos que a redação de El País.com (que está junto com a redação de El País) conta com cerca de 20 jornalistas, que se dedicam exclusivamente a ElPaís. com. Na Prisacom há diferentes tipos de profissionais que destinam parte de seu tempo ao jornal digital. Por isso é difícil saber com exatidão o número de profissionais envolvidos na execução de ElPaís. com. Certo é que conseguiram compartilhar de maneira notável o material informativo do grupo.

\section{Grupo Folha}

A Folha de S. Paulo, jornal editado na cidade de São Paulo, é um dos produtos mais importantes do Grupo Folha, pois é o jornal de maior circulação no Brasil e um dos mais influentes do país. A história desse grande grupo de comunicação brasileiro, e com grande repercussão em toda América Latina, começa em 1921, muito antes da Folha de S. Paulo ser batizada com este nome.

Os anos 1980 foram um período de consolidação para o jornal, como o mais vendido do país. Essa posição foi conquistada principalmente durante a campanha pela redemocratização do país, em 1984. Naquele ano foi publicado o primeiro "Projeto Editorial", que defendia um jornalismo crítico, pluralista, apartidário e moderno. Essas metas pautariam o trabalho da Folha nas décadas seguintes.

Em 24 de setembro de 1989, motivada pelo êxito das experiências do jornal espanhol El País e do norte-americano The Washington Post, a Folha passou a publicar a coluna do seu ombudsman.

Em 1995, o Grupo Folha iniciava uma nova e prometedora fase com a criação de uma empresa destinada ao mercado na internet. Esse acontecimento permitiu que o grupo fosse o primeiro jornal 
no Brasil a oferecer conteúdo on-line. Em 1996, o grupo ampliou seus negócios e estreou o Universo Online (UOL). Suas principais características, e que o deixava desde então diferente no mercado brasileiro de internet, era haver nascido pautado no conceito de ser um provedor de internet com um grande portal de serviços, informação, entretenimento, e uma atividade muito próspera, o comércio eletrônico.

Controladora tanto de UOL como da Empresa Folha da Manhã, que publica a Folha, a família Frias mantém o controle de FolhaUOL, o segundo conglomerado de mídia do Brasil.

A Folha seguiu crescendo e se converteu em um grupo de comunicação que abarca internet, novos jornais, instituto de pesquisas, agências, editora de livros e revistas, e a maior gráfica de impressão off-set do país.

\section{Folha Online}

O grande salto do Grupo Folha veio quando uma equipe de profissionais da Agência Folha, em colaboração com a redação do jornal Folha de S. Paulo, começou a colocar notícias da edição impressa em um site denominado Folha Web. Era a primeira tentativa do grupo de compreender a dinâmica da rede e estava seguindo a tendência das publicações da época. A Folha Web era um projeto simples, realizado por uma equipe de três pessoas, e não possuía seu próprio servidor.

Em abril de 1996, a Folha Web foi substituída pela fase experimental do Universo Online, dando lugar à web da Folha de S.Paulo com a reprodução completa da edição do dia, os arquivos das edições anteriores e as notícias em tempo real. O UOL cresceu rapidamente e abarca a publicação das revistas do Grupo Abril, que passou a ser seu sócio, além de muitas outras informações e serviços. Com esta fusão, em 1997, o portal UOL passa a ter grande parte de seus conteúdos sob pago.

A Folha decidiu então criar seu próprio site, a Folha Online, e passou a fornecer conteúdo jornalístico ao UOL. O portal continuou com sua redação em um dos edifícios do Grupo Folha, produzindo principalmente informação em economia, entretenimento e arte. E por outro lado, está a Folha Online desenvolvendo todo tipo de informação jornalística. A Folha Online sempre teve todo seu conteúdo de acesso gratuito, exceto a versão digital do jornal Folha de S. Paulo, que pode ser consultado tanto por assinantes do jornal, como pelos assinantes do UOL.

Em 2003, a proposta de criar um "Erramos" se concretizou, e a Folha Online passou a assumir publicamente seus "erros". Atitude que fortalece a credibilidade dos leitores e, conseqüentemente, a dos anunciantes. Nessa época se gerou um incremento do investimento de publicidade, as contas da Folha Online se estabilizaram em um lucro líquido real, iniciando um período de constante crescimento. 
A Folha Online estreou seu novo projeto em 2007 com várias mudanças, muitas delas inspiradas por idéias dos próprios leitores, que enviam diariamente sugestões e reclamações.

Há atualmente mais ferramentas de participação e interação entre os leitores e o jornal digital. O novo serviço de comentários de reportagens está disponível para matérias previamente selecionadas. Quando um leitor quer enviar sua opinião sobre alguma matéria, o tema em discussão que não esteja entre as reportagens selecionadas pode ser expresso na sessão "Painel do leitor". Os usuários também podem colaborar com o conteúdo do jornal web enviando notícias e fotos. Toda participação do leitor antes de ser publicada passa pela leitura de um jornalista. O editor-chefe Ricardo Feltrin nos informou que ferramentas como "Eu, jornalista" só podem existir nos ciberjornais que tenham um controle de tudo o que é publicado, verificando a fonte.

Outra novidade foi que os próprios leitores podem avaliar as mensagens enviadas pelos internautas. Com isso, a Folha Online criou um espaço de interação entre seus usuários.

Também no ano de 2007, o jornal começou a planejar a implantação do primeiro estúdio de vídeo, que deverá demorar alguns anos para ser bem realizado. Segundo Feltrin, a qualidade de transmissão dos vídeos atualmente no Brasil ainda é baixa, mesmo com internet de banda larga.

\section{A equipe responsável da folha Online}

A fusão do trabalho entre as redações papel e digital é total e ambas participam das mesmas reuniões e entendem que podem se beneficiar com a coordenação do trabalho. Mas nem sempre foi assim. No primeiro ano da fusão, os jornalistas da redação impressa não aceitavam bem a idéia e tinham dificuldade de trabalhar juntos.

Por ocasião deste levantamento, eram cerca de 60 pessoas, 35 mulheres e 25 homens; são aproximadamente 45 jornalistas, mais quatro webdesigners, um programador, dois infografistas, três na área de fotografia e mais o pessoal de publicidade; o salário é baseado em tempo de casa e mérito. O piso salarial é idêntico ao do jornalismo impresso (cerca de $\mathrm{R} \$ 2.700$ ) e são três turnos de oito horas. Pela madrugada há somente um jornalista.

Os jornalistas da redação digital estão distribuídos entre suas editorias e são responsáveis pela atualização de notícias. Entretanto, são capazes de atualizar as notícias de diversas editorias, já que nos fins de semana há uma redução considerável de pessoal, e esses poucos jornalistas são os responsáveis por cobrir todo o ciberjornal.

Toda a rotina de trabalho muda quando ocorre um feito de repercussão mundial. Quando eventos dessa natureza sucedem, a redação se esquematiza para ter uma cobertura 24 horas em cima do tema. 


\section{Organizações Globo}

O ciberjornal é simplesmente um dos muitos veículos entre as muitas e diferentes plataformas de um conglomerado de empresas brasileiras concentradas na área de mídia e comunicação. O maior grupo de comunicação do Brasil está incluso entre os maiores do mundo no âmbito da comunicação de massa.

Sua história começa em 1925, no Rio de Janeiro, a partir do jornal $O$ Globo, a partir do qual se formaria todo um império de outras empresas e produtos sempre nas mãos da família Marinho.

A Infoglobo é a empresa dentro das Organizações Globo responsável pela mídia jornalística impressa e digital. Tem como principal objetivo a informação mais completa, sempre com a preocupação de adequar a linguagem ao público a que se destina. O Globo é líder absoluto no Rio de Janeiro das classes A e B. Com a mesma credibilidade e público alvo qualificado, merece destaque também o desempenho do $O$ Globo Online.

\section{O Globo.com}

Em julho de 1996, o jornal O Globo decidiu publicar na internet sua versão digital. A princípio, a web se limitava a reproduzir as edições diárias do jornal, com só algumas informações complementares. Em 1998, O Globo Online adotava uma postura mais atuante na cobertura diária dos acontecimentos do Brasil e do mundo e, pouco a pouco, começava a montar sua própria equipe de jornalistas. Em 1999 mantinha uma atualização permanente de notícias funcionando quase as 24 horas do dia. O Globo Online se fortaleceu como uno dos principais noticiários eletrônicos do país e não parou de crescer.

Em 2003 O Globo Online percebeu que era necessária uma nova forma de fazer jornalismo na internet. A partir desse momento, começaram a dar alguma atenção para os multimídias. Desde 2004 iniciaram com uma tímida produção de vídeos que a cada ano recebe mais cuidado, pois estão cada vez mais seguros que o leitor deseja acessar informação nesse formato.

Em 2005, O Globo Online continuou inovando, experimentou novas linguagens, levando os leitores a ambientes especiais multimídia, chegando a produzir naquele ano 110 especiais, que se demonstraram um êxito de audiência.

Em 2006, em comemoração ao décimo aniversário, o site elaborou várias novidades. A participação do leitor se tornou mais efetiva. Em janeiro, foi criado o ambiente chamado "Resoluções 2006", em que dez leitores contaram durante esse ano suas experiências para cumprir as metas traçadas na virada do ano. Na cobertura da Copa 2006, outros dez leitores - cinco no Brasil e cinco na Alemanha - relataram sua paixão pelo Brasil.

Desde o dia 12 de agosto de 2006, o usuário encontrou uma web inteiramente nova. Além de uma inteira reformulação de desenho,

${ }^{2}$ http://oglobo.globo. com/especiais/resolucoes/ 
o ciberjornal passou a incentivar o jornalismo participativo, com a criação de um editorial dedicado exclusivamente à publicação de material enviado pelos leitores. A produção de mais conteúdo multimídia também está entre as principais apostas da web, que investiu alto na aquisição de novos equipamentos para a produção e edição de vídeo, além da iniciativa de instruir nesse campo a equipe de repórteres e editores.

O redesenho de 2006 foi uma transformação estética grande, mas sobretudo de conceito, sobre o ciberjornal. Que fez com que os jornalistas trabalhem de modo diferente, trazendo o leitor para dentro do site, com opinião e conteúdo. "Não foi fácil fazer essa mudança conceitual. de passar do jornalismo que se escreve só, para fazer um jornalismo que se constrói a informação junto com o leitor", nos contou Raquel Almeida, diretora de conteúdos.

\section{A equipe responsável por 0 Globo Online}

A maneira como está organizada a equipe de trabalho é independente da organização do jornal impresso. Há certa sinergia, caminham para uma integração, mas não se sabe nem quando, nem como isso passará. Atualmente seguem a mesma linha editorial, mas são completamente independentes. Entretanto, as duas redações estão sempre em contato.

$\mathrm{Na}$ área de produção de conteúdo trabalham cerca de 80 pessoas. Um grande grupo está no Rio de Janeiro, mas também há jornalistas em São Paulo e Brasília. Todos esses jornalistas produzem e reproduzem informação no jornal on-line, sempre verificando mais detalhes sobre a notícia e as complementando. Os jornais que abastecem $O$ Globo Online pertencem ao mesmo Grupo Globo. Há uma cota de conteúdo que as redações devem enviar por dia. Segundo Raquel Almeida, esse sistema funciona, mas poderia ser melhor se os jornais trabalhassem mais próximos. A jornalista afirmou que ainda há uma distância entre o papel e o digital.

Os jornalistas da área de produção de conteúdo estão divididos, como no jornal impresso, por sessões. Cada editorial tem um subeditor, ou repórter que está a um nível mais alto que os demais jornalistas da mesma editoria. No momento deste levantamento, havia ao redor de três profissionais coordenadores de projetos, cinco editores de capa, oito editores divididos entre as diferentes sessões, 40 jornalistas, 14 profissionais em multimídia, oito profissionais na área de tecnologia, à parte de uma editora-chefa, dois editores executivos e uma editora de conteúdos.

A faixa de idade da maioria dos editores da edição on-line é entre os 35 e 40 anos. Entretanto, há jornalistas mais jovens. Para Raquel Almeida, o que melhor funciona é a mescla entre pessoas mais velhas e jovens que trazem uma formação diferente. 
Os salários dos editores de $O$ Globo Online são equivalentes a um subeditor em $O$ Globo papel. Em geral todos os salários da redação digital são inferiores aos do jornal impresso, independente do sexo ou tempo de experiência na casa. Segundo Raquel Almeida, isso ocorre porque o ciberjornalismo é ainda considerado um jornalismo inferior ao feito em papel ou na televisão. Porém, ela o percebe melhor visto e aceito de quando começou a trabalhar na redação on-line.

Dentro da redação digital, os jornalistas têm um constante intercâmbio de informação baseado no "boca-a-boca". Quando algo de muita relevância nacional o internacional sucede, a rotina da redação muda para que haja uma melhor cobertura. Um aspecto interessante da atualização da capa é que qualquer proposta deve ser levada pessoalmente, qualquer jornalista de outra sessão que queira propor algo para a capa deve se dirigir até os editores dela. É válido enviar as propostas por e-mail, mas é necessário ir e dizer olho no olho.

O trabalho da produção e atualização de notícias se passa dentro de cada editoria, que trabalham independentes uma das outras. Porém há liberdade para que os jornalistas de uma editoria complementem a informação de outra, pois há jornalistas que têm uma formação bastante híbrida, que lhes permite fazer positivamente esse trânsito.

A redação detectou que às 11 horas o conteúdo da página já deve estar bem apresentado, pois às 12 horas ocorre o primeiro horário de grande visitação. Depois o fluxo de visita volta a aumentar às 17 horas, e o último incremento de número de visitas é às 21 horas, mais ou menos depois das notícias na televisão.

Os jornalistas da redação on-line tardaram em perceber a necessidade de mudança na forma de apresentar a notícia escrita. Foi preciso mostrar as estatísticas de navegação para a maioria dos jornalistas perceberem que uma notícia extensa, de muitas telas, não era lida, em contrapartida àquela de uma única tela e cinco links, foi toda navegada e muito mais lida. Esta resistência se deve principalmente ao fato que esses jornalistas vêm de uma formação totalmente dirigida ao jornalismo impresso. Apenas 10\% da redação somente trabalharam em ciberjornalismo. Os demais vêm todos da época do "papel".

Raquel Almeida demonstrou contentamento ao explicar que toda a produção multimídia é feita na redação on-line. Há 14 pessoas na criação. Desses profissionais, três se dedicam exclusivamente a vídeos. Ela considera que ainda é um número baixo. A produção de vídeo existe desde 2005, mas a busca do leitor está crescendo rapidamente, o que sugere que esse número tende a aumentar. No momento estão buscando uma linguagem para os vídeos. Sabem que não podem ser TV, se equivocam, têm acertos, vão se desfa-

Os salários dos
editores de 0
Globo Online são
equivalentes a um
subeditor de 0 Globo
em papel. Em geral
todos os salários da
redação digital são
inferiores aos do
jornal impresso

Os salários dos editores de 0 Globo Online são equivalentes a um subeditor de $\boldsymbol{O}$ Globo em papel. Em gera todos os salários da redação digital são jornal impresso 
zendo de formas e tentando outras. É uma linguagem que está em construção. A editora de conteúdos acredita que a melhor e maior transformação que presenciou em seus seis anos trabalhando em ciberjornalismo são a produção e utilização dos multimídias. Sabe que ainda, em alguns momentos, o ciberjornal se parece à maneira tradicional do jornalismo impresso, por falta de braços capazes para desenvolver rapidamente as ferramentas multimídias.

A partir de 2005 abriram o site para uma maior participação do leitor. Raquel acrescenta que foi de forma tardia, e que deixar participar não é simplesmente oferecer enquetes e foros. Entretanto, em 2006, com a mudança de desenho e de conceito introduzido com a nova portada, se criaram mais possibilidades de estimular a participação do leitor. Os usuários participam enviando textos e fotos. O ciberjornal acreditava que o usuário também enviaria muitos vídeos, mas ainda a participação com esta ferramenta não é tão grande.

O Globo Online estreou sua comunidade de leitores, batizada de Globoonliners, e atualmente está destinada aos assuntos mais variados. Para participar das discussões e ter seu próprio blog pessoal é preciso se registrar. Os usuários também são convidados a enviar sugestões de melhorias.

O Globo Online, como sucede na maioria dos ciberjornais, tem a produção digital gratuita, e o acesso a qualquer conteúdo de $O$ Globo tradicional é pago. Podem acessar os assinantes, ou a outra opção é comprar unicamente a edição desejada.

\section{Reflexões finais}

Os jornais digitais estudados vêm de grandes grupos de comunicação, e desses grupos incorporaram determinadas características. La Vanguardia é o jornal mais antigo e o produto mais importante do Grupo Godó, por isso a dificuldade de apostar realmente em sua versão digital e dar a ela mais força. Seja através da coordenação entre ambas as diretorias, seja através do acréscimo do número de profissionais que se dedicam à versão digital, ou seja, ainda, através de investimento em recursos que possibilitem mais multimídia e a participação do usuário. La Vanguardia tardou a assimilar que necessitava investir na versão digital, porém, desde 2006, La Vanguardia.es está passando por transformações positivas e tentando recuperar o tempo perdido. Essas mudanças e o incremento da planilha seguiram crescendo em 2007 e 2008, trazendo à La Vanguardia.es a melhoria constante de seu produto e o aumento de visitas.

Por outro lado, El País esperou um pouco mais. Conseqüentemente, sua estréia na rede foi com um ciberjornal mais estudado e elaborado. A redação digital já se iniciava com nove jornalistas e dois técnicos responsáveis pela publicação do jornal na rede, uma quantidade considerável para o princípio de todos os demais ciber- 
jornais. Isso demonstra que o jornal aspirava em se fazer notável. Seu crescimento foi contínuo, alternando momentos com mais ou menos visitas, dependendo do modelo de negócio que estabelecia. Do jornal impresso aprendeu a seguir inovando, e do Grupo Prisacom a coordenar e compartilhar o material dos diferentes meios do grupo. Foi um dos jornais da Espanha a apostar mais fortemente na multimídia. Também saiu na frente na questão da participação do usuário. No entanto, é um ciberjornal fechado em determinados aspectos. Para esse trabalho, foi o mais difícil de conseguir informação. Outro aspecto que pode ser questionado, em uma tendência natural em que os "ciberjornalistas" atuam em diversas áreas, é que haja um grupo de jornalistas em uma redação (de El País) e outro grupo de profissionais em outro edifício (Prisacom). Como decorrência, por exemplo, os jornalistas da atualização de notícias trabalham em edifícios separados dos que produzem multimídia.

Sobre multimídia, um exemplo muito diferente aos dois acima citados é $O$ Globo Online. Dos ciberjornais estudados é o que realmente leva mais a sério essa linguagem. Uma iniciativa é a de dar instruções para que os próprios jornalistas, que já trabalham na redação, possam produzir material audiovisual, além de ter um grupo próprio de 14 profissionais, consideravelmente grande em comparação com outros ciberjornais. A redação se sente orgulhosa (e reconhecidamente) de que toda a produção multimídia seja realizada dentro de "casa". Outro aspeto positivo deste ciberjornal é o modo como assimilam o leitor num jornalismo participativo. É também o jornal digital com mais iniciativas a esse respeito. De maneira geral, a participação do leitor na construção do ciberjornalismo vem ganhando espaço. O que não se pode perder de vista é que haja jornalistas dentro das redações, e, como mínimo, sirvam de mediadores dessa informação, e não permitam plágios, ofensas, racismo e outras repercussões negativas que possam existir.

O exemplo que atua com muito cuidado a esse respeito é a Folha Online, que caminha modestamente com os multimídia e os espaços dedicados à participação dos leitores. Contudo, segue líder de audiência no Brasil, e isso se deve principalmente a sua preocupação e seriedade na hora de informar os leitores. A Folha sempre foi conhecida por sua credibilidade, um dos princípios que constantemente pautaram seus projetos editoriais. Percebe-se, assim, que a Folha Online não está ousando, provando. É um ciberjornal cauteloso na hora de informar e está abrindo espaço para multimídia e para a participação dos leitores à medida que essas iniciativas não comprometam a veracidade da notícia e o compromisso que tem com seus patrocinadores e leitores. A Folha Online necessita encontrar o caminho para seguir informando com qualidade, porém incorporando, cada vez mais, proximidade ao seu leitor e oferecer avances tecnológicos e linguagem multimídia que esses desejam encontrar em um ciberjornal.

\section{A Folha Online caminha modestamente com os multimídia e os espaços dedicados à participação dos leitores. Contudo, segue líder de audiência no Brasil}


Um ponto forte em comum entre os ciberjornais estudados é que entre os anos de 2006 e 2007 todos eles passaram por modificações profundas em suas redações. E querem responder aos novos desafios do jornalismo on-line e às crescentes necessidades informativas dos internautas. As mudanças são óbvias e não há nenhuma revolução, e sim uma evolução. Se um jornal já tem qualidade, não há porque fazer um grande salto, e sim há que perceber que é necessário evoluir, principalmente quando se trata de um suporte que utiliza novas tecnologias. Os jornais digitais já vinham fazendo pequenas modificações e melhorias, mas não anunciavam cada mudança, porque um bom ciberjornal está provando e se ajustando constantemente às mudanças tecnológicas e às necessidades do usuário.

Todavia, houve anos em que estas transformações foram mais contundentes, como se pode apreciar nos anos de 2006 e 2007. Algumas tendências são possíveis notar. Todos os ciberjornais tiveram modificações em seus desenhos, que facilitam a navegação do leitor. Também em maior ou menor grau, todos eles abriram mais espaço para multimídia e a participação mais efetiva do leitor. Faz tempo que se sabe que essas duas características são indispensáveis para um ciberjornalismo de qualidade, mas durante muito tempo elas cresceram paulatinamente, apenas ganhando mais força nos últimos anos.

A maior vantagem para um grupo de comunicação que tem a representação de seu jornal na rede é o fortalecimento da marca em todos os suportes e a conquista de novos leitores. As vantagens para os jornalistas são as aberturas de um campo inimaginado de possibilidades de produção de notícia e a proximidade com o leitor, o feedback deste. É um mundo em que as possibilidades se ampliam profundamente, desde produzir vídeos, infografia ou criar um blog. O ciberjornalismo também possibilita uma grande inserção trabalhista aos jornalistas. Por outro lado, para o leitor, este se beneficia pela agilidade do meio digital, pela possibilidade de interatuar com a fonte. De dar sua opinião, de ajudar a elaborar o ciberjornal, seja com críticas e sugestões ou com o envio de material.

No jornalismo impresso a autoria está clara, é quem escreve e assina a notícia. No entanto, isto na maioria dos casos não é possível no ciberjornalismo. A autoria se faz mais fluida, mais compartida, a notícia se transforma nas mãos de um jornalista ao chegar de uma agência e recebe uma ferramenta multimídia que não foi realizada apenas por um único profissional. A idéia do jornalista multimídia que é bom em tudo não existe. Porém é preciso treinar o jornalista para fazer todas as atividades, já que, na hora da necessidade, ele pode desenvolver as distintas ferramentas de comunicação. Sobretudo treinar a visão do ciberjorna-

A idéia do jornalista
multimídia que é
bom em tudo não
existe. Porém é
preciso treinar
o jornalista para
desenvolver
as distintas
ferramentas de
comunicação

A idéia do jornalista multimídia que é existe. Porém é preciso treinar o jornalista para desenvolver as distintas comunicação 
lista, para que este saiba olhar uma informação e saber qual é a melhor maneira de informar o leitor. Identificar se a notícia tem potencial para ser texto, foto, áudio, vídeo ou infográfico.

Os ciberjornais estudados têm em comum a busca de mudanças que se relacionem com a revolução da informação, com os novos meios e ferramentas jornalísticas e com as profundas modificações nos hábitos dos leitores.

\section{Referências}

www.circulacao.org.br - Instituto Verificador de Circulação.

www.elpais.com

www.folha.uol.com.br

www.jupiterresearch.com

www.lavanguardia.es

MANUAL de Redação. Folha de S. Paulo. Publifolha: São Paulo, 2001.

DIAZ NOCI, J. e SALAVERRIA, R. (coords.). Manual de redacción ciberperiodistica. Barcelona: Ariel, 2003.

FREITAS, H. Nem tudo é notícia: O Grupo Folha na Internet. Tese de Mestrado da Universidade Metodista de São Bernardo do Campo, 1999.

RIGHETTII, S.; QUADROS, R. Inovação tecnológica, formação de competências e diversificação no mercado da comunicação: a introdução da internet em dois grupos brasileiros de mídia impressa. Intercom: Santos, 2007.

SALAVERRÍA, Ramón (coord.). Cibermedios - El Impacto de Internet en los medios de comunicación en España. Sevilla: Comunicación Social, 2005.

Recebido em 30 de agosto de 2008

Aprovado em 25 de outubro de 2008 